\title{
Cancer Incidence Projections in the United States Between 2015 and 2050
}

\author{
Hannah K. Weir, $\mathrm{PhD}^{1}$; Trevor D. Thompson, BS ${ }^{1}$; Sherri L. Stewart, $\mathrm{PhD}^{1}$; Mary C. White, ScD ${ }^{1}$
}

\begin{abstract}
Accessible Version: www.cdc.gov/pcd/issues/2021/21_0006.htm
Suggested citation for this article: Weir HK, Thompson TD,

Stewart SL, White MC. Cancer Incidence Projections in the United States Between 2015 and 2050. Prev Chronic Dis 2021; 18:210006. DOI: https://doi.org/10.5888/pcd18.210006.
\end{abstract}

\section{PEER REVIEWED}

\section{Summary}

What is already known on this topic?

In the United States, the number of adults entering the age groups at greatest risk for being diagnosed with cancer is increasing.

What is added by this report?

Between 2015 and 2050, we predict the total number of cancer cases to increase by almost $50 \%$ as a result of the growth and aging of the US population. The largest increase is anticipated in adults aged $\geq 75$ years.

What are the implications for public health practice?

Projecting cancer cases can help the public health community plan and evaluate community intervention strategies aimed at reducing the growing number of cancer cases by reducing cancer risk across the lifespan.

\section{Abstract}

\section{Introduction}

The number of adults entering the age groups at greatest risk for being diagnosed with cancer is increasing. Projecting cancer incidence can help the cancer control community plan and evaluate prevention strategies aimed at reducing the growing number of cancer cases.

\section{Methods}

We used data from the Surveillance, Epidemiology, and End Results Program and the US Census Bureau to estimate average, annual, age-standardized cancer incidence rates and case counts (for all sites combined and top 22 invasive cancers) in the US for 2015 and to project cancer rates and counts to 2050 . We used age, period, and cohort models to inform projections.

\begin{abstract}
Results
Between 2015 and 2050, we predict the overall age-standardized incidence rate (proxy for population risk for being diagnosed with cancer) to stabilize in women (1\%) and decrease in men $(-9 \%)$. Cancers with the largest change in risk include a $34 \%$ reduction for lung and bronchus and a $32 \%$ increase for corpus uterine $(32 \%)$. Because of the growth and aging of the US population, we predict that the annual number of cancer cases will increase $49 \%$, from 1,534,500 in 2015 to 2,286,300 in 2050, with the largest percentage increase among adults aged $\geq 75$ years. Cancers with the largest projected absolute increase include female breast, colon and rectum, and prostate.
\end{abstract}

\section{Discussion}

By 2050, we predict the total number of incident cases to increase by almost $50 \%$ as a result of the growth and aging of the US population. A greater emphasis on cancer risk reduction is needed to counter these trends.

\section{Introduction}

In the US, cancer is the leading cause of death in midlife and may soon become the leading cause of death overall as the number of people diagnosed with and dying from cancer continues to increase $(1,2)$. Paradoxically, over the past several decades the overall age-standardized cancer incidence rates have stabilized and death rates have declined steadily. The age-standardized rate can be used as a proxy for the population's risk of being diagnosed with or dying from cancer and is useful for comparing risk between populations or over time within a population. However, the age-standardized rate effectively removes the underlying influence of demographic changes in the population. The risk of being diagnosed with cancer generally increases with age, and over this period the US population has grown, particularly in the older age groups $(2,3)$. Thus, the increase in the number of incident cases and deaths reflects, to a large extent, the impact of a growing and aging population. This demographic trend is expected to continue as a larger proportion of the Baby Boom and Gen X cohorts sur- 
vive to older ages compared with earlier generations and enter the age groups most at risk for a cancer diagnosis.

Trends in cancer incidence rates (population risk) and projections of population growth and age structure have been used to predict cancer incidence including in the US (4), Canada (5), England (6), the Nordic countries (7), and for world regions broadly (8). Predicting the growth in the number of incident cases in the US can help health planners and policy makers anticipate the resources needed to diagnose, treat, and care for future cancer patients and cancer survivors. Cancer-specific projections can also help the public health community to plan and evaluate risk reduction strategies and alert researchers to early changes in population risk.

In this study, we used data from the National Cancer Institute's Surveillance, Epidemiology, and End Results (SEER) Program to estimate nationwide, age-standardized, 5-year average annual cancer incidence rates and case counts (all sites and top 22 cancers) for the US population for 2015 and to project rates and counts to 2050 .

\section{Methods}

\section{Data sources}

We obtained data for patients diagnosed with invasive cancer from 1996 through 2015 from the SEER Program, which covered approximately $14 \%$ of the US population (9). The file included in situ bladder cancer cases because these cancers are considered invasive for the purpose of incidence reporting (10). Population estimates used as rate denominators were a modification of annual county age- and sex-specific population estimates produced by the US Census Bureau's Population Estimates Program, in collaboration with the Centers for Disease Control and Prevention's (CDC's) National Center for Health Statistics and with support from the National Cancer Institute (11). We obtained population projections of the resident population (Middle Series) by age and sex from 2016 through 2050 from the US Census Bureau's Population Projections Program (12).

\section{Analytic methods}

We used SEER* stat to calculate age-specific and age-standardized rates for cancer patients of all ages who were diagnosed with invasive cancer (other than nonmelanoma skin cancer) from 1996 through 2015. All invasive cancers were selected and grouped according to the top 22 cancers and all other remaining sites combined among men and women. We estimated nationwide, annual incident counts for 2015 by applying 5-year age-specific incidence rates (2011-2015) to the 2011-2015 US population estimates and dividing by 5 . Similarly, projections for 2050 were calcu- lated by annualizing rates and population projections for the 2046-2050 period. Methods for projecting cancer incident cases in the US have been published previously $(4,5)$. Briefly, to project cancer incidence rates from 2016 through 2050, we used NORDPRED software, available from the Cancer Registry of Norway website (www.kreftregisteret.no/en/Research/Projects/Nordpred/ Nordpred-software/) (7). The program used age-period-cohort regression models with input data aggregated into four 5-year calendar periods (1996-2000, 2001-2005, 2006-2010, 2011-2015) and 15 age groups (15-19 years through $\geq 85$ years). Separate models were fit for each cancer site by sex and all races combined: $\mathrm{R}_{\mathrm{ap}}=$ $\left(A_{a}+D \cdot p+P_{p}+C_{c}\right)^{5}$ in which the dependent variable $R_{a p}$ is the incidence rate in age group a in calendar period $p . A_{a}$ is the age component for age group a, D is the drift parameter (the common linear effect of both calendar period and birth cohort), $\mathrm{P}_{\mathrm{p}}$ is the nonlinear period component of period $\mathrm{p}$, and $\mathrm{C}_{\mathrm{c}}$ is the nonlinear cohort component of cohort $\mathrm{c}$. When using the regression models as the basis for projected rates for each cancer site and sex group, the starting age criterion was that each age group contain 10 or more cases. Projections for age groups below that starting criterion were based on the average rates from the past 10 years. Separate models were fit for each cancer site by sex. To offset exponential increases or decreases in incidence rates, we used the power-5 link function. Assuming that trends are not likely to continue indefinitely, the drift component in the model was reduced by $25 \%$ in the second calendar period, by $50 \%$ in the third calendar period, and by $75 \%$ in the fourth and fifth periods. These modifications have been shown empirically to improve predictions (7).

We based projections on 20 years of data (1996-2015) unless significant curvature in the trend was found over time. When curvature occurred, the linear drift component was based on the most recent 10 -year period. Projections for all sites combined were summed estimates for the cancer sites categories, including other cancer sites combined. For thyroid cancer, we used a modified approach to account for recent concerns that overdiagnosis may inflate projections (13). We based projections for thyroid cancers on age-specific rates for thyroid cancer diagnosed from 2011 through 2015 because recent thyroid incidence rates are no longer increasing (14). For female breast and prostate cancer, we used a modified approach to account for breast cancer incidence decreases in the early 2000 s attributed to a reduction in the use of hormone replacement therapy and fluctuations in prostate cancer incidence related to the use of the prostate-specific antigen test $(15,16)$. For these cancers, we had the trends taper off sooner by applying $25 \%, 50 \%$, and $75 \%$ reductions in the first 3 calendar periods and truncating the trends (ie, 100\% reduction) in the fourth and fifth periods.

The opinions expressed by authors contributing to this journal do not necessarily reflect the opinions of the U.S. Department of Health and Human Services, the Public Health Service, the Centers for Disease Control and Prevention, or the authors' affiliated institutions. 
NordPred provides projections for up to five 5-year periods; thus, age-specific incidence rates were projected for the 5-year calendar periods 2016-2020, 2021-2025, 2026-2030, 2031-2035, and 2036-2040. Projections for 2041-2045 and 2046-2050 were generated by applying the 2036-2040 age-specific incidence rates to corresponding population projections because the greatest driver in overall cancer incident cases has been the growth and aging of the US population (4).

We calculated the absolute and relative difference between estimated 2015 and projected 2050 age-standardized incidence rates and case counts. Annual estimated and projected incident cases and absolute differences were rounded to the nearest 100th for presentation in tables.

\section{Results}

Table 1 shows the distribution of estimated and projected annual counts of all cancer incident cases for 2015 and 2050, respectively, by age. The total number of cases is predicted to increase by $49 \%$ from $1,534,500$ (2015) to $2,286,300$ annual cases (2050). In each age group, the total number of cases is predicted to increase. The largest percent increase was projected for adults aged $\geq 85$ years followed by adults aged 75-84 years (Figure 1). In 2015, it is estimated that $842,200(55 \%)$ of cancer patients were diagnosed at aged $\geq 65$ years. In 2050 , we predict that $1,446,000(63 \%)$ of all patients diagnosed with cancer will be aged $\geq 65$ years, an increase of 603,800 annual cases from 2015.

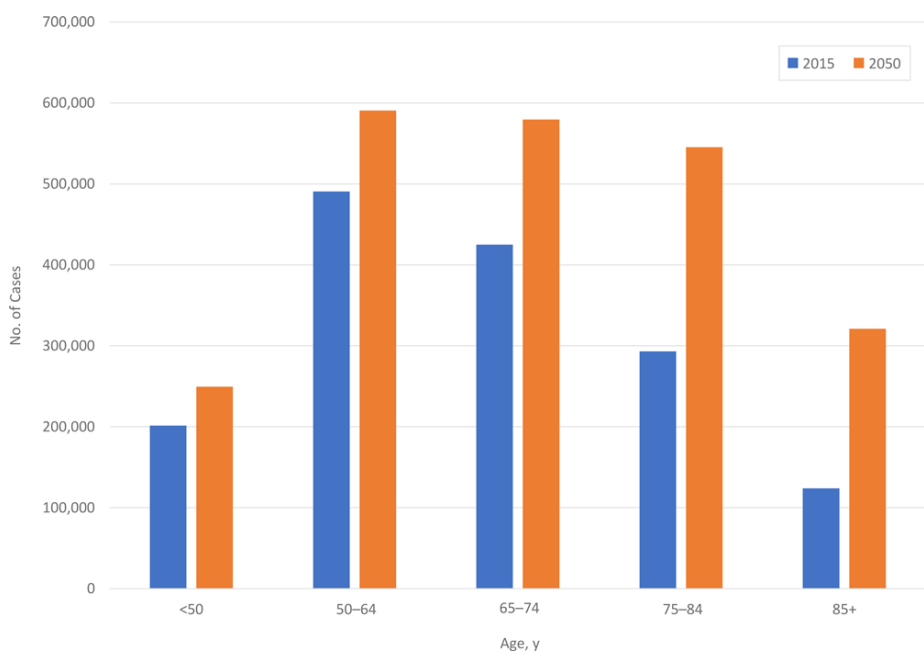

Figure 1. Distribution of estimated 2015 and projected 2050 average annual cancer cases (all sites combined), by age group, United States. Numbers may not sum to total because of rounding.

Table 2 shows estimated 2015 and projected 2050 average annual age-standardized incidence rates and case counts. The top 4 can- cers (female breast, prostate, lung and bronchus, and colon and rectum) accounted for $49 \%$ of all incident cases in 2015 and are projected to account for $46 \%$ of all incident cases in 2050 . Cancer sites in which there is projected to be a relative percentage increase of $10 \%$ or more in age-standardized rates include female breast, kidney and renal pelvis, corpus and uterus, liver and intrahepatic bile duct, and myeloma. The largest absolute and relative increases in incident cases are expected in female breast $(123,900$; $52 \%)$, prostate $(82,300 ; 43 \%)$, colon and rectum $(67,900 ; 50 \%)$, and melanoma of the skin $(48,000 ; 63 \%)$.

Cancer sites projected to have fewer than an additional 10,000 annual incident cases between 2015 and 2050 are cancers of the ovary, brain and nervous system, esophagus, cervix uteri, and larynx. No increase in additional incident cases for Hodgkin lymphoma is predicted. Cancer sites with a predicted relative decrease of $10 \%$ or more are lung and bronchus, non-Hodgkin lymphoma, urinary bladder, esophagus, cervix uteri, larynx, and Hodgkin lymphoma.

Figure 2 shows the rank order of average annual incident cases estimated to be diagnosed in 2015 and the additional number of annual cases predicted to be diagnosed in 2050 . Female breast, prostate, colon and rectum, and lung and bronchus are projected to remain the 4 leading cancers in 2050. In 2015, cancers of the lung and bronchus were estimated to be the third leading cancer diagnosed in men and women followed by colorectal cancers. By 2050, the number of colorectal cancers is predicted to exceed the number of cancers of the lung and bronchus.

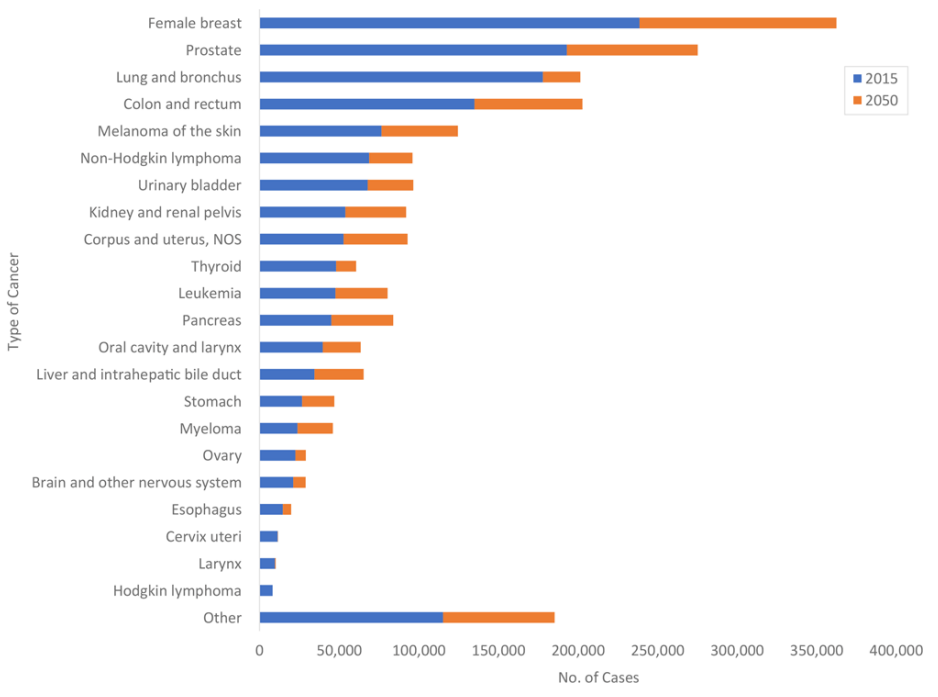

Figure 2. Estimated (2015) cancer cases and projected additional cases (2050) by cancer site, United States. Numbers may not sum to total because of rounding. Abbreviation: NOS, not otherwise specified.

The opinions expressed by authors contributing to this journal do not necessarily reflect the opinions of the U.S. Department of Health and Human Services, the Public Health Service, the Centers for Disease Control and Prevention, or the authors' affiliated institutions. 


\section{Discussion}

Over the next several decades, we predict the total number of cancer incident cases (excluding nonmelanoma skin cancer) to increase by nearly $50 \%$, from $1,534,500$ in 2015 to $2,286,300$ in 2050. As the size of the US population increases, incident cases are expected to increase in all age groups, but the largest percentage increases will occur among adults aged $\geq 75$ years. Over this period, overall cancer risk is predicted to stabilize in women $(1 \%)$ and decline slightly ( $-9 \%)$ among men. Thus, the increase in the total number of incident cases will reflect primarily demographic changes related to a growing and aging population.

The demographic components underlying the increase in incident cases are being driven initially by adults born between 1946 and 1964 (the Baby Boom cohort). In 2011, adults in this generation began turning 65 years of age and by 2029, all will be aged 65 years or older. In addition to the increase in the number of incident cases, the number of people living with a history of cancer (cancer survivors) also is expected to increase. Improvements in early detection and cancer treatment of some common cancers resulted in an overall increase in 5-year cancer survival for all cancers combined, from $49 \%$ for patients diagnosed in the 1970 s to $70 \%$ for patients diagnosed in the 2010s (14). An increase in the number of people who receive a cancer diagnosis and high 5-year survival for common cancers like cancers of the female breast and prostate have resulted in an increase in the number of cancer survivors. In 2019, the number of cancer survivors was estimated to be 16.9 million and is projected to reach 22.1 million by 2030 (17). Cancer survivors require ongoing care and surveillance because they are at increased risk for additional cancer diagnoses, as well as other chronic diseases (18). The increase in number of cancer survivors has profound implications for health care and cancer surveillance resource needs in the US, including the need for oncology specialists and certified tumor registrars $(19,20)$. In addition, the costs of cancer care are substantial, increasing, and not sustainable $(21,22)$.

The projections in this study assume that cancer incidence patterns will continue largely unchanged for the next few decades with the 4 leading cancers (female breast, prostate, colon and rectum, and lung and bronchus) accounting for just under $50 \%$ of all cancer cases. If the prevalence of causal factors associated with higher cancer risk declined in the population, so too could cancer incidence. Multiple opportunities exist to disrupt the initiation or promotion of different cancers in adults by reducing exposures to carcinogens, promoting social and physical environments that support healthy behaviors, and preventing chronic conditions such as obesity and diabetes $(23,24)$. The Community Guide (www.thecommunityguide.org/) provides recommended community-based strategies to reduce the prevalence of several common behavioral risk factors. Expanded research on environmental cancer and on interventions to reduce inequities in cancer risk could provide additional opportunities to lower cancer incidence in the future $(25,26)$.

A comprehensive cancer control plan can provide a roadmap for public health action to reduce the burden of cancer. Individual state, tribal, and territorial cancer plans in 66 jurisdictions across the US are developed by participants in CDC's National Comprehensive Cancer Control Program (NCCCP) (27). Program participants can use these findings to prioritize Community Guide and other evidence-based interventions in their plans to help reduce the expected increases in particular cancers, either through the reduction of cancer risk factors or the medical treatment of precancerous conditions, such as the removal of polyps during screening colonoscopy or treatment of cervical lesions detected by Papanicolaou (Pap) tests (27). The NCCCP has historically focused on many of the cancers that are expected to increase in total numbers (female breast, colon and rectum, melanoma, lung and bronchus [through tobacco control], and liver and hepatic duct cancers). In addition to the continued prioritization of these cancers, our data suggest that an expansion of NCCCP's focus may be warranted in the near term to include reduction and control of cancers of the kidney and renal pelvis and the corpus and uterus. In California, efforts focused on the primary prevention of breast cancer offered an innovative model for integrating scientific evidence on multiple risk factors with community perspectives to develop an action plan (28).

Our analysis has strengths and limitations. Age-period-cohort models identify trends in younger birth cohorts and extrapolate these trends to future older cohorts. These models have been used in many population-based studies, and the methods have been validated using long-term cancer incidence data (7). However, these predictions should be viewed with caution. First, the SEER data covered $14 \%$ of the US population, which tended to be more urban and have more foreign-born individuals compared with other parts of the US. As a result, incidence rates based on data from SEER found that 14 areas differed somewhat from data based on National Program of Cancer Registries (NPCR) areas, with prostate incidence higher and lung cancer incidence lower (29). Second, changes in risk factor exposures, screening recommendations, and advances in medical techniques are likely to occur between now and 2050. Finally, population projections are themselves forecasts based on assumptions regarding future births, deaths, and migration and can therefore affect projections of incident counts and rates. Therefore, although our predictions are based on the best available information, they should be updated periodic-

The opinions expressed by authors contributing to this journal do not necessarily reflect the opinions of the U.S. Department of Health and Human Services, the Public Health Service, the Centers for Disease Control and Prevention, or the authors' affiliated institutions. 
ally in consultation with cancer surveillance subject matter experts when combined long-term data from SEER and NPCR become available and as revised population projections become available.

Our projections make it clear that, to mitigate the impact of a growing and aging population, a substantial, robust, and coordinated focus on primary prevention is needed. If these efforts are to have any significant impact on the number of future cancer cases, they must be implemented immediately, owing to the long latency period for many cancers.

\section{Acknowledgments}

This work was supported by CDC. The findings and conclusions in this report are those of the authors and do not necessarily represent the official position of CDC. No copyrighted materials or tools were used in this research.

\section{Author Information}

Corresponding Author: Hannah K. Weir, PhD, 4770 Buford Highway, Mailstop S107-4, Atlanta, GA 30341. Telephone: 770488-3006. E-mail: hbw4@cdc.gov.

Author Affiliations: ${ }^{1}$ Division of Cancer Prevention and Control, Centers for Disease Control and Prevention, Atlanta, Georgia.

\section{References}

1. Weir HK, Anderson RN, Coleman King SM, Soman A, Thompson TD, Hong Y, et al. Heart disease and cancer deaths - trends and projections in the United States, 1969-2020. Prev Chronic Dis 2016;13:160211.

2. US Cancer Statistics Working Group. US Cancer Statistics Data Visualizations Tool, based on 2019submission data (1999-2017). https://www.cdc.gov/cancer/uscs/dataviz/ index.htm. Accessed April 28, 2021.

3. Ortman JM, Velkoff VA, Hogan H. An aging nation: the older population in the United States. https://www.census.gov/ content/dam/Census/library/publications/2014/demo/p251140.pdf. Accessed April 28, 2021.

4. Weir HK, Thompson TD, Soman A, Møller B, Leadbetter S. The past, present, and future of cancer incidence in the United States: 1975 through 2020. Cancer 2015;121(11):1827-37.

5. Poirier AE, Ruan Y, Walter SD, Franco EL, Villeneuve PJ, King WD, et al.; ComPARe Study Team. The future burden of cancer in Canada: long-term cancer incidence projections 2013-2042. Cancer Epidemiol 2019;59:199-207.
6. Smittenaar CR, Petersen KA, Stewart K, Moitt N. Cancer incidence and mortality projections in the UK until $2035 . \mathrm{Br} \mathrm{J}$ Cancer 2016;115(9):1147-55.

7. Møller B, Fekjaer H, Hakulinen T, Sigvaldason H, Storm HH, Talbäck M, et al. Prediction of cancer incidence in the Nordic countries: empirical comparison of different approaches. Stat Med 2003;22(17):2751-66.

8. Bray F, Møller B. Predicting the future burden of cancer. Nat Rev Cancer 2006;6(1):63-74.

9. SEER Program. SEER*Stat Database: Incidence - SEER Research Data, 9 Registries, Nov 2019 Sub (1975-2017), Linked To County Attributes, Time Dependent (1990-2017) Income/Rurality, 1969-2017 Counties, National Cancer Institute, DCCPS, Surveillance Research Program, released April 2020, based on the November 2019 submission.

10. Hankey BF, Edwards BK, Ries LA, Percy CL, Shambaugh E. Problems in cancer surveillance: delineating in situ and invasive bladder cancer. J Natl Cancer Inst 1991;83(6):384-5.

11. National Cancer Institute. Surveillance, Epidemiology, and End Results (SEER) Program. Population Estimates Used in NCI's SEER*Stat Software. SEER Program, National Cancer Institute; 2019. http://seer.cancer.gov/popdata/methods.html. Accessed April 28, 2021.

12. US Census Bureau. 2017 National Population Projections Datasets. https://www.census.gov/data/datasets/2017/demo/ popproj/2017-popproj.html. Accessed April 28, 2021.

13. Ellison LF, Bushnik T. Changing trends in thyroid cancer incidence in Canada: a histologic examination, 1992 to 2016. Health Rep 2020;31(1):15-25.

14. Howlader N, Noone AM, Krapcho M, Miller D, Brest A, Yu M, et al., editors. SEER Cancer Statistics Review, 1975-2017, National Cancer Institute. Bethesda (MD): National Cancer Institute. https://seer.cancer.gov/csr/1975_2017/. Accessed April 28, 2021.

15. DeSantis C, Howlader N, Cronin KA, Jemal A. Breast cancer incidence rates in U.S. women are no longer declining. Cancer Epidemiol Biomarkers Prev 2011;20(5):733-9.

16. Hankey BF, Feuer EJ, Clegg LX, Hayes RB, Legler JM, Prorok PC, et al. Cancer surveillance series: interpreting trends in prostate cancer - part I: evidence of the effects of screening in recent prostate cancer incidence, mortality, and survival rates. J Natl Cancer Inst 1999;91(12):1017-24.

17. Miller KD, Nogueira L, Mariotto AB, Rowland JH, Yabroff $\mathrm{KR}$, Alfano CM, et al. Cancer treatment and survivorship statistics, 2019. CA Cancer J Clin 2019;69(5):363-85.

18. Mariotto AB, Enewold L, Zhao J, Zeruto CA, Yabroff KR. Medical care costs associated with cancer survivorship in the United States. Cancer Epidemiol Biomarkers Prev 2020; 29(7):1304-12.

The opinions expressed by authors contributing to this journal do not necessarily reflect the opinions of the U.S. Department of Health and Human Services, the Public Health Service, the Centers for Disease Control and Prevention, or the authors' affiliated institutions. 
19. Yang W, Williams JH, Hogan PF, Bruinooge SS, Rodriguez GI, Kosty MP, et al. Projected supply of and demand for oncologists and radiation oncologists through 2025: an aging, better-insured population will result in shortage. J Oncol Pract 2014;10(1):39-45.

20. Chapman SA, Mulvihill L, Herrera C. Workload and time management in central cancer registries: baseline data and implication for registry staffing. J Registry Manag 2012; 39(4):178-84.

21. Park J, Look KA. Health care expenditure burden of cancer care in the United States. Inquiry 2019;56:46958019880696.

22. Trogdon JG, Tangka FK, Ekwueme DU, Guy GP Jr, Nwaise I, Orenstein D. State-level projections of cancer-related medical care costs: 2010 to 2020. Am J Manag Care 2012; 18(9):525-32.

23. White MC, Holman DM, Boehm JE, Peipins LA, Grossman M, Henley SJ. Age and cancer risk: a potentially modifiable relationship. Am J Prev Med 2014;46(3Suppl 1):S7-15.

24. White MC, Holman DM, Goodman RA, Richardson LC. Cancer risk among older adults: time for cancer prevention to go silver. Gerontologist 2019;59(Suppl 1):S1-6.

25. Kripke M, Brody JG, Hawk E, Hernandez AB, Hoppin PJ, Jacobs MM, et al. Rethinking environmental carcinogenesis. Cancer Epidemiol Biomarkers Prev 2020;29(10):1870-5.

26. Alcaraz KI, Wiedt TL, Daniels EC, Yabroff KR, Guerra CE, Wender RC. Understanding and addressing social determinants to advance cancer health equity in the United States: a blueprint for practice, research, and policy. CA Cancer J Clin 2020;70(1):31-46.

27. Pyron T, Fonseka J, Young M, Zimmerman L, Moore AR, Hayes N. Examining comprehensive cancer control partnerships, plans, and program interventions: successes and lessons learned from a utilization-focused evaluation. Cancer Causes Control 2018;29(12):1163-71.

28. White MC, Kavanaugh-Lynch MMHE, Davis-Patterson S, Buermeyer N. An expanded agenda for the primary prevention of breast cancer: charting a course for the future. Int J Environ Res Public Health 2020;17(3):714.

29. Wingo PA, Jamison PM, Hiatt RA, Weir HK, Gargiullo PM, Hutton $\mathrm{M}$, et al. Building the infrastructure for nationwide cancer surveillance and control - a comparison between the National Program of Cancer Registries (NPCR) and the Surveillance, Epidemiology, and End Results (SEER) Program (United States). Cancer Causes Control 2003;14(2):175-93.

The opinions expressed by authors contributing to this journal do not necessarily reflect the opinions of the U.S. Department of Health and Human Services, the Public Health Service, the Centers for Disease Control and Prevention, or the authors' affiliated institutions. 


\section{Tables}

Table 1. Distribution of Estimated (2015) and Projected (2050) Average ${ }^{a}$ Annual Counts of Cancer Cases (All Sites Combined) and Percentage Change, by Age, United States

\begin{tabular}{|l|c|c|c|}
\hline \multirow{2}{*}{ Age, $\mathbf{y}$} & $\mathbf{2 0 1 3}$ & $\mathbf{2 0 4 8}$ & $\mathbf{2 0 1 3 - 2 0 4 8}$ \\
\cline { 2 - 4 } & No. (\%) & No. (\%) & No. Change (\% Change) \\
\hline$<50$ & $201,500(13)$ & $249,500(11)$ & $48,000(24)$ \\
\hline $50-64$ & $490,700(32)$ & $590,700(26)$ & $100,000(20)$ \\
\hline $65-74$ & $425,000(28)$ & $579,500(25)$ & $154,500(36)$ \\
\hline $75-84$ & $293,200(19)$ & $545,400(24)$ & $252,200(86)$ \\
\hline$\geq 85$ & $124,000(8)$ & $321,100(14)$ & $197,100(159)$ \\
\hline Total & $1,534,500(100)$ & $2,286,300(100)$ & $751,900(49)$ \\
\hline
\end{tabular}

a 2015 Estimated counts are average annual counts of cancer incident cases diagnosed 2011-2015. 2050 Projected counts are average annual counts of cancer incident cases projected to be diagnosed 2045-2050. 
Table 2. Estimated (2015) and Projected (2050) Age-Standardized Incidence Rates, Average Annual Case Counts and Percentage Change by Cancer Site

\begin{tabular}{|c|c|c|c|c|c|c|c|c|}
\hline \multirow[b]{2}{*}{ Cancer Site } & \multirow[b]{2}{*}{ Sex } & \multicolumn{3}{|c|}{ Age-Standardized Rates } & \multicolumn{4}{|c|}{ Average Annual Case Counts } \\
\hline & & 2015 & 2050 & $\%$ Change & 2015 & 2050 & Difference, No. & \% Change \\
\hline All cancer sites & Both & 428.9 & 412.6 & -4 & $1,534,500$ & $2,286,300$ & 751,800 & 49 \\
\hline All cancer sites & Male & 467.1 & 425.0 & -9 & 766,700 & $1,149,600$ & 382,900 & 50 \\
\hline All cancer sites & Female & 404.3 & 407.2 & 1 & 767,800 & $1,136,700$ & 368,900 & 48 \\
\hline Breast & Female & 127.0 & 139.5 & 10 & 238,800 & 362,700 & 123,900 & 52 \\
\hline Prostate & Male & 110.9 & 101.9 & -8 & 193,200 & 275,500 & 82,300 & 43 \\
\hline Lung and bronchus & Both & 49.7 & 32.5 & -34 & 178,100 & 201,700 & 23,600 & 13 \\
\hline Lung and bronchus & Male & 57.5 & 37.1 & -35 & 91,500 & 106,200 & 14,700 & 16 \\
\hline Lung and bronchus & Female & 43.9 & 28.6 & -35 & 86,600 & 95,500 & 8,900 & 10 \\
\hline Colon and rectum & Both & 37.9 & 38.8 & 3 & 135,100 & 203,000 & 67,900 & 50 \\
\hline Colon and rectum & Male & 43.3 & 44.5 & 3 & 70,200 & 111,700 & 41,500 & 59 \\
\hline Colon and rectum & Female & 33.3 & 33.6 & 1 & 64,900 & 91,300 & 26,400 & 41 \\
\hline Melanoma of the skin & Both & 21.9 & 20.9 & -5 & 76,700 & 124,700 & 48,000 & 63 \\
\hline Non-Hodgkin lymphoma & Both & 19.5 & 16.3 & -16 & 68,900 & 96,100 & 27,200 & 39 \\
\hline Urinary bladder & Both & 19.0 & 14.4 & -24 & 68,000 & 96,700 & 28,700 & 42 \\
\hline Kidney and renal pelvis & Both & 15.1 & 17.0 & 13 & 54,000 & 92,100 & 38,100 & 71 \\
\hline Corpus and uterus, NOS & Female & 26.9 & 35.5 & 32 & 52,800 & 93,100 & 40,300 & 76 \\
\hline Thyroid & Both & 14.5 & 14.4 & -1 & 48,100 & 60,700 & 12,600 & 26 \\
\hline Leukemia & Both & 13.8 & 14.3 & 4 & 47,700 & 80,500 & 32,800 & 69 \\
\hline Pancreas & Both & 12.5 & 13.4 & 7 & 45,200 & 84,100 & 38,900 & 86 \\
\hline Oral cavity and pharynx & Both & 10.9 & 11.6 & 7 & 39,700 & 63,600 & 23,900 & 60 \\
\hline Liver and intrahepatic bile duct & Both & 9.2 & 10.4 & 14 & 34,500 & 65,400 & 30,900 & 90 \\
\hline Stomach & Both & 7.5 & 8.0 & 7 & 26,700 & 47,000 & 20,300 & 76 \\
\hline Myeloma & Both & 6.7 & 7.6 & 14 & 23,900 & 46,100 & 22,200 & 93 \\
\hline Ovary & Female & 11.9 & 11.3 & -5 & 22,500 & 29,100 & 6,600 & 29 \\
\hline Brain and other nervous system & Both & 6.2 & 6.2 & -1 & 21,200 & 29,000 & 7,800 & 37 \\
\hline Esophagus & Both & 4.0 & 3.3 & -19 & 14,700 & 19,900 & 5,200 & 35 \\
\hline Cervix uteri & Female & 6.9 & 5.4 & -21 & 11,400 & 11,600 & 200 & 1 \\
\hline Larynx & Both & 2.6 & 1.8 & -31 & 9,700 & 10,200 & 500 & 6 \\
\hline Hodgkin lymphoma & Both & 2.5 & 2.0 & -23 & 8,200 & 7,800 & -400 & -5 \\
\hline Other & Both & 33.2 & 32.6 & -2 & 115,400 & 185,500 & 70,100 & 61 \\
\hline
\end{tabular}

Abbreviation: NOS, not otherwise specified.

The opinions expressed by authors contributing to this journal do not necessarily reflect the opinions of the U.S. Department of Health and Human Services, the Public Health Service, the Centers for Disease Control and Prevention, or the authors' affiliated institutions. 